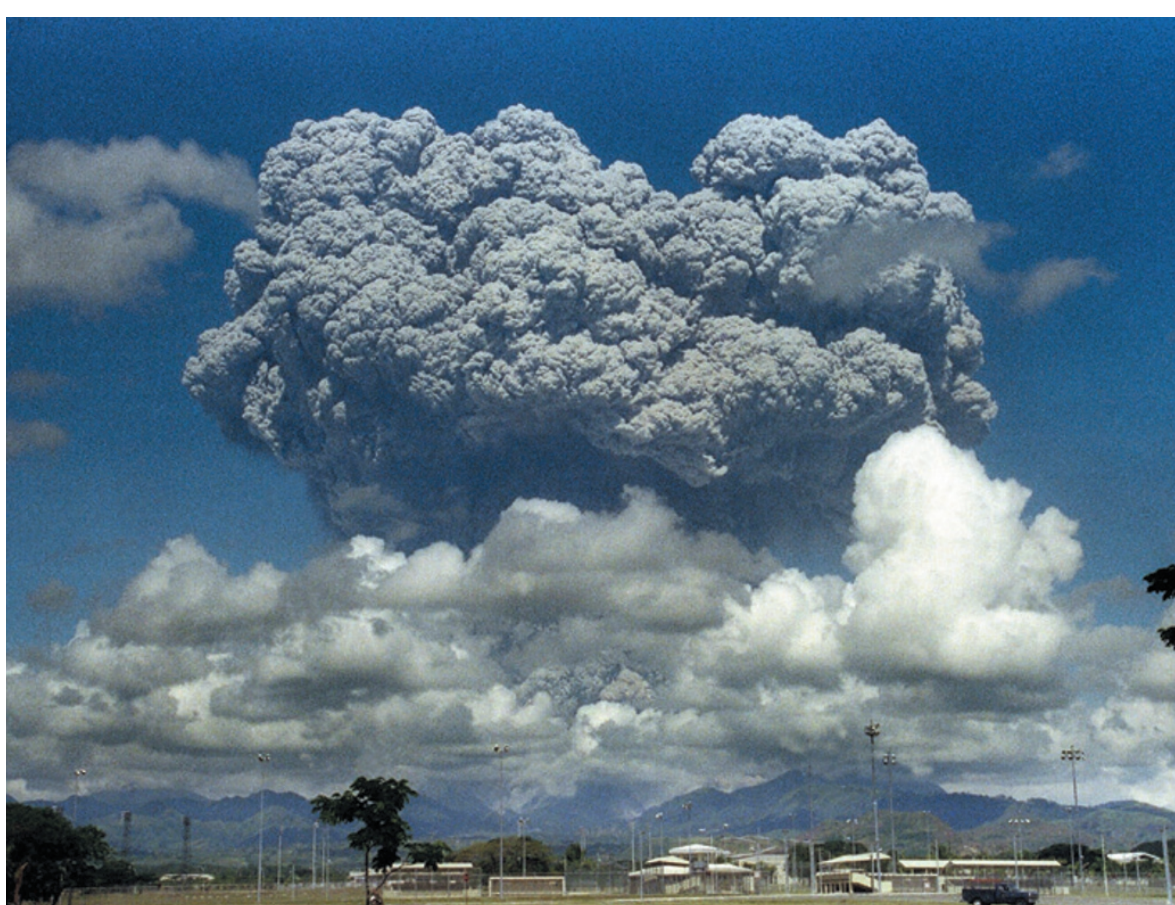

The eruption of Mount Pinatubo in the Philippines in June 1991 cooled the globe.

GEOENGINEERING

\section{One cool solution}

\section{Nicola Jones finds a treatise on a proposed global- warming fix intriguing, but isn't converted to the cause.}

$\mathrm{I}$ $\mathrm{t}$ is 2030, and a fleet of ten Gulfstream business jets have been converted to a new purpose: dispensing 250,000 tonnes of sulphates a year into the lower stratosphere. Here the chemicals form sunlightreflecting droplets that cool the planet below. This artificial volcanic haze, costing about US\$700 million a year, helps to mitigate the warming effect of greenhouse gases.

This is the vision of David Keith, a physicist and self-described "oddball environmentalist”. His company, Carbon Engineering, is currently pursuing a device that can suck carbon dioxide out of the air (see Nature 458, 1094-1097; 2009). Now, in A Case for Climate Engineering, Keith considers the partner concept of cooling the world by deflecting sunlight. Unlike journalist Eli Kintisch's 2010 book Hack the Planet, this is not an exploration of all geoengineering schemes told through compelling stories and characters. Rather, it is a straightforward presentation of one controversial, planet-altering idea along with an intriguing discussion of the philosophical roots of environmentalism.

Mopping up carbon dioxide, as Keith's company aims to do, is expensive but carries no global risk. Conversely, sulphate spraying is very cheap: the cost A Case for Climate be just a few billion MIT Press: 2013. dollars, compared to the $\$ 300$ billion being spent per year globally on clean-energy technologies, writes Keith. But the possible downsides range from disrupting rainfall and interfering with the ozone layer to creating acid rain and removing political incentives to reduce emissions.

Keith is a member of the 'geo-clique', a small group of researchers who have spent serious time considering such schemes. His work has earned him everything from being named a 2009 'Hero of the Environment' by Time magazine to outrage from colleagues and even death threats. Geoengineering has been labelled crazy: geophysicist Ray Pierrehumbert called it "barking mad". And just last month, former Royal Society head Martin Rees dubbed it "an utter political nightmare".

Sulphates are certainly effective coolants. Atmospheric sulphur dioxide from the 1991 eruption of Mount Pinatubo cooled the globe by $0.5^{\circ} \mathrm{C}$ in less than a year. Since the 1970s, a few scientists have explored the logistics and risks of mimicking this process. of a decade's worth of Engineering Sun-blocking might DAVID KEITH
It has become apparent, for example, that counteracting all greenhouse-gas warming with sulphates would result in a world with less rainfall. Keith's group has found, however, that countering just a fraction of the world's warming with sulphates could mitigate the rainfall changes caused by our current emissions of greenhouse gases. For this reason, among others, Keith prefers to investigate a Sun-shading scheme that aims to counter just half of the world's temperature rise (for example, reducing a catastrophic rise of $4{ }^{\circ} \mathrm{C}$ to $2{ }^{\circ} \mathrm{C}$, the "upper bound of acceptable warming"), and only for a limited time.

But there are problems. The cooling action of sulphates doesn't follow the same pattern as the warming action of carbon dioxide: sulphates are more effective during the day and in summer, for example, whereas carbon dioxide acts all year round. Nor can sulphates counteract ocean acidification. And the resulting air pollution would probably cause thousands of deaths each year from asthma, heart disease and lung cancer, writes Keith. There are few facts and figures in the book with which to weigh up these dangers: the risk of acid rain, for example, he simply dismisses as "relatively small" compared to the hazards of rapid climate change.

Strangely unmentioned in Keith's book is the United Nations ban against geoengineering. In 2008, the United Nations Convention on Biological Diversity enacted a moratorium against iron fertilization - the idea of sprinkling iron into the ocean to feed phytoplankton and thus soak up atmospheric carbon dioxide. This ban was extended in 2010 to all temperature-fiddling geoengineering projects, including Sun-blocking schemes.

The moratorium, which is intended to prevent commercial projects or large-scale efforts while allowing for small-scale experimentation, has been used by protestors to try to block all iron-fertilization experimentation. Keith's book might be a pre-emptive strike against things going the same way for solar geoengineering; he and his colleagues are contemplating small-scale experiments now.

Keith's goal with this book, he writes, is to convince us that deciding whether or not to pursue geoengineering is a "hard choice", not an easy decision based on instinctive revulsion. He succeeds, but this is a low bar. Where he fails is in convincing us to agree with him that "deliberate haste" is called for.

General readers will probably find $A$ Case for Climate Engineering a bit dry; academics might judge it too light. But it should stand as an enticing starter for the researchers who Keith hopes to rope into the field, thereby expanding the 'geo-clique' and helping to push the science into the mainstream.

Nicola Jones is a freelance science journalist based near Vancouver, Canada. e-mail:nkjones@gmail.com 